\title{
Fluorescent Oligonucleotides - Versatile Tools as Probes and Primers for DNA and RNA Analysis
}

\author{
Christian Wojczewski, ${ }^{a}$ Karen Stolze, ${ }^{b}$ Joachim W. Engels ${ }^{a, *}$ \\ ${ }^{a}$ Institut für Organische Chemie, Johann Wolfgang Goethe-Universität, Marie-Curie-Str. 11, \\ 60439 Frankfurt am Main, Germany \\ Fax: (+49) 69798 29148; E-mail: engels@ews1.org.chemie.uni-frankfurt.de \\ ${ }^{\mathrm{b}}$ Institut für Organische und Bioorganische Chemie, Humboldt-Universität zu Berlin, Hessische Straße 1-2, \\ 10115 Berlin, Germany \\ Received 8 August 1999
}

\begin{abstract}
Different strategies for the fluorescence labeling of nucleosides and oligonucleotides and techniques for their detection are discussed. Pre- and post-synthetic routes as well as automated solid phase-based syntheses and enzymatic methods are compared. Tailor-made chemical syntheses are presented that meet the requirements of a broad spectrum of applications for oligonucleotides as probes.
\end{abstract}

Key words: fluorescent oligonucleotides, automated solid-phase synthesis, modified nucleosides, fluorescence spectroscopy, DNA

\section{$1 \quad$ Introduction}

Fluorescence based techniques are powerful tools for the investigation of biological material. Until the last decade, radioactive labeling procedures and UV measurements were preferred whenever only smallest amounts of a sample were available. However, the employment of lasers instead of lamps, combined with the development of sophisticated optical instruments and the supply of new fluorescent dyes with optimized properties has turned fluorescence spectroscopy into a superior method. The sensitivity has reached an extremely high level, being several orders of magnitude better than UV detection and even topping radioactive techniques. The process of fluorescence emission occurs in a time scale between nanoseconds and milliseconds, dependent on the fluorescence system used. Since in this time scale many dynamic events take place, fluorescence can provide information on the structure, mobility, macromolecular size, distances, or conformational rearrangements of dye-bound molecules. ${ }^{1}$

Fluorescent nucleic acids in particular are important tools in molecular biology, diagnostics and structural studies. Nucleic acids are heteropolymers and consist of four different monomers. DNA consists of a $2^{\prime}$-deoxyribose $5^{\prime}$ phosphate backbone and the four heterocyclic bases adenine (A), cytosine (C), guanine (G), and thymine (T), connected through an $\mathrm{N}$-glycosidic bond, RNA contains a ribose 5'-phosphate backbone and the base uracil (U) instead of thymine. The term 'oligonucleotide' represents short segments of these nucleic acids from about 10 up to 100 monomer building blocks. Whereas proteins may contain fluorescent amino acids like tryptophane, the intrinsic fluorescence emission of the five most frequent nu- cleobases A, C, G, T, and $\mathrm{U}$ is too weak to be of considerable use for biological applications. ${ }^{2}$ Furthermore, natural fluorescent nucleobases like wyosin from transfer RNA do not occur frequently. Thus, in order to make oligonucleotides fluorescent, a wide range of chemical and enzymatic methods were developed. Unlike radioisotopes, dyes may exert an undesirable influence on the structure and mobility of the sample. Even little changes in the conformation of a nucleic acid can lead to a reduced specificity of hybridization with its target. For the organic chemist, therefore, it is a challenge to develop nucleic acid analogues and procedures for different applications that do not disturb the functions of the nucleic acids investigated. An overview of these methods shall be given in this article.

\section{Automated Solid Phase DNA Synthesis}

The predominant method for oligonucleotide synthesis nowadays is the phosphoramidite approach introduced by Beaucage and Caruthers..$^{3-6}$ The synthesis is performed on a solid phase like glass with controlled pore width (CPG) and starts with the $5^{\prime}$-end deprotection of the CPG-bound nucleoside (Figure 1). The generated free hydroxyl group reacts with the 3'-phosphoramidite of the following nucleoside which has to be activated with $1 H$-tetrazole for a smooth and fast reaction. Remaining hydroxyl groups are capped to prevent elongation of missense strands. The resulting dinucleoside phosphite is oxidized to the corresponding phosphate with a mixture of iodine in water, and the cycle starts again. At the end of synthesis, ammonia is used to release the product from the solid surface and to deprotect the exocyclic amino groups of the nucleobases. Up to date, intensive optimization of the phosphoramidite approach led to a remarkably good tool for the chemical synthesis of oligonucleotides with coupling times lower than one minute and coupling efficiencies higher than 99\% per base for DNA or ten minutes and $98 \%$ for RNA, respectively. ${ }^{7}$

Regarding the modular system of this synthetic procedure, the covalent introduction of fluorescent groups at specific positions of any DNA or RNA sequence is easily performed. 


\section{Fluorescence Techniques}

Fluorescence can be characterized by excitation and emission wavelengths, quantum yield, decay time, and polarization. Fluorescence excitation and emission spectra provide information on energies of transitions. However, since there are several other processes which compete with fluorescence emission, not the whole number of excited molecules emit fluorescence radiation. This can be characterized by the fluorescence quantum yield (the ratio of the number of the quanta emitted to the number of quanta absorbed) and decay time (which is the time after that the number of excited molecules is reduced to 1/e).
Fluorescence anisotropy reflects the relative orientations of electronic absorption and emission dipoles, and from its decay it is possible to receive information on the rotational behavior of the chromophore in a macromolecule. ${ }^{8}$

During the last years fluorescent based techniques have become more and more attractive since their detection limit even in routine assays today is exceptionally high. To date there are approaches to detect even fluorescent single molecules. ${ }^{9}$ Due to their ease of use fluorescent nucleic acid probes are useful tools in qualitative and quantitative analysis involving fluorescence in situ hybridization, fluorescence quenching / dequenching, emission anisotropy, or fluorescence resonance energy

\section{Biographical Sketches}
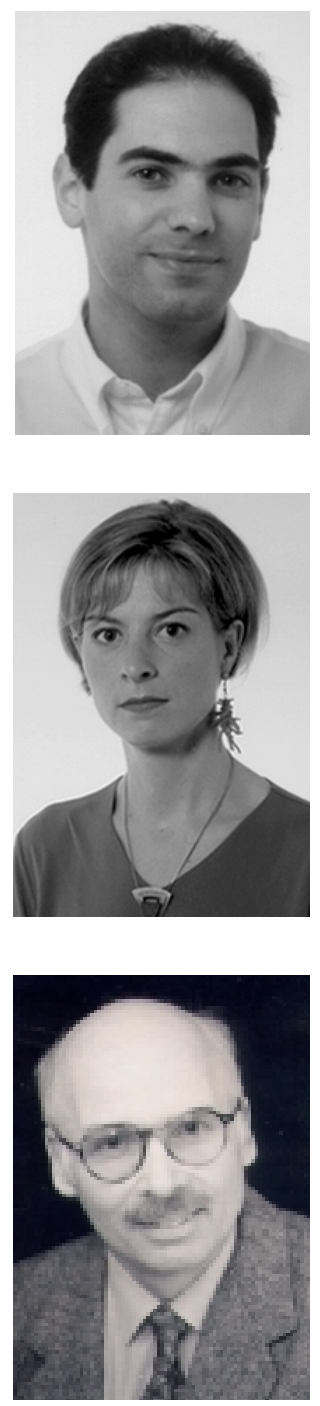

Christian Wojczewski was born in Frankfurt, Germany in 1971. He studied chemistry at the University of Frankfurt where he obtained his diploma in 1995 . He is currently completing his
$\mathrm{Ph} . \mathrm{D}$. thesis in the group of Prof. J. W. Engels on the synthesis of modified nucleotides for DNA sequencing.
Karen Stolze was born in Berlin, Germany in 1970. She studied chemistry at Technische Universität in Dresden and HumboldtUniversität in Berlin where she obtained her diploma in 1995. She is currently completing her Ph.D. thesis under supervision of Prof. Dr. D. Cech in Berlin and Prof. Dr. J. W. Engels in Frank- furt on the synthesis of modified nucleotides for enzymatic DNA sequencing techniques.
Joachim W. Engels received a Vordiplom from FUBerlin 1966 and a Diplom from LMU-München in 1969. After obtaining a Dr. from Regensburg University under the direction of Professor Jürgen Sauer where he learned mechanistic organic chemistry, he spent a postdoctorate with E.E. van Tamelen at Stanford in 1973 exploring nucleotides and rare bases. Back in Germany at the Konstanz University as Ha- bilitand in the group of Prof. W. Pfleiderer he explored cyclic phosphates as Pro Drugs and developed caged cAMP. After Habilitation in Organic Chemistry 1979 he joined Hoechst Company and stayed as a visiting researcher with Prof. Marve Caurthers in Boulder, Colorado. There he was introduced to Solid phase DNASynthesis and recombinant DNA techniques. From $1981-85$ as a scientist at Hoechst he was involved in gene synthesis (like Hirudin) and their expression in E.coli. Since 1985 he is Professor of Organic Chemistry and Biotechnology at the Goethe University Frankfurt. He is engaged in oligonucleotide chemistry and its application as therapeutics like Antisense, Triplex and Ribozyme. As a hobby he fancies secretion of proteins in Streptomyces and studies their folding. 


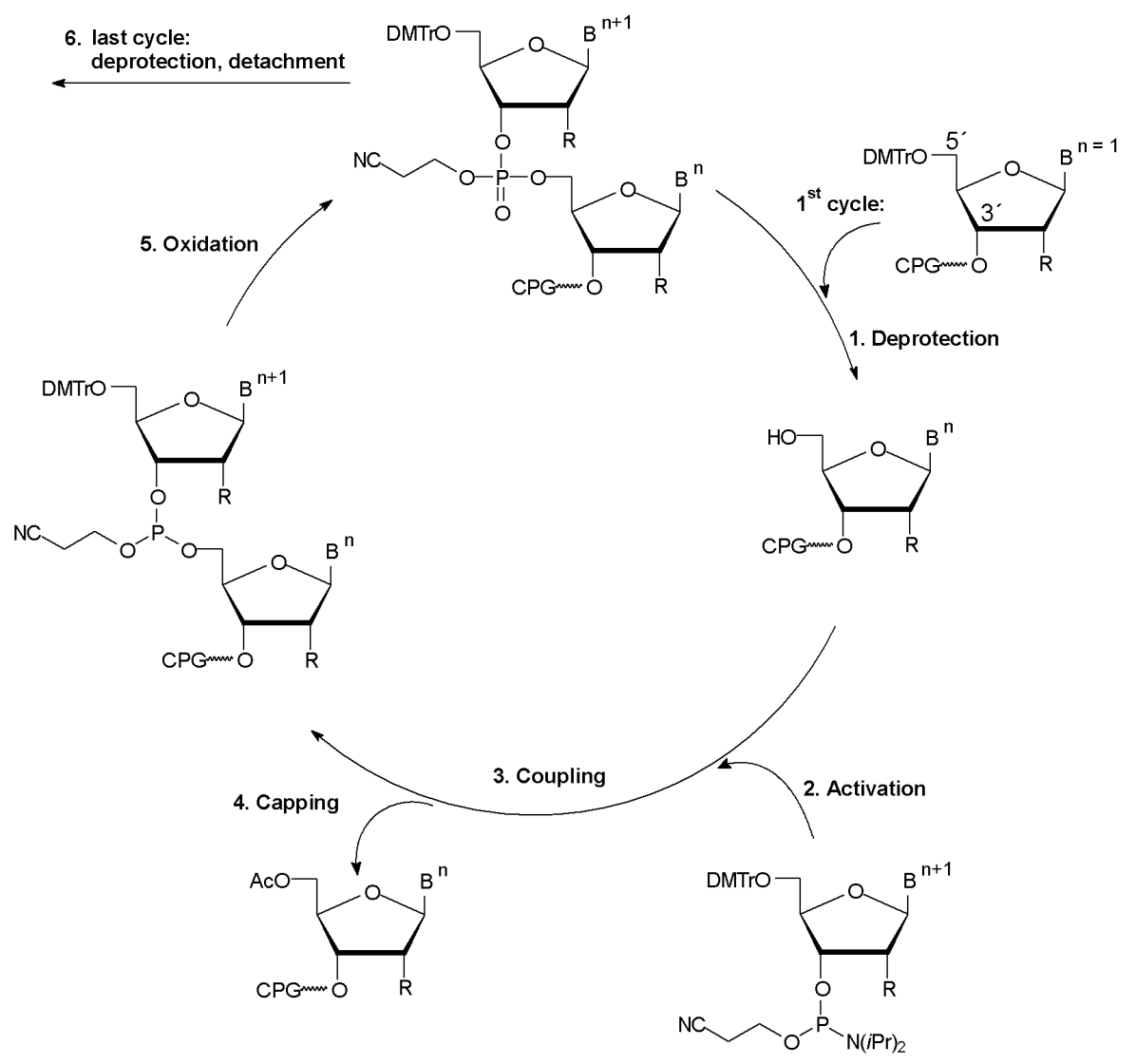

The oligonucleotide reaction cycle. DMTr $=4,4^{\prime}$-dimethoxytriphenylmethyl; $\mathrm{CPG}=$ controlled pore glass; $\mathrm{B}=$ base; $\mathrm{n}=$ number of nucleoside; $\mathrm{R}=\mathrm{H}$ (DNA) or protected $\mathrm{OH}$ (RNA); The addition of one phosphoramidite to the growing chain consists of four chemical steps: detritylation (1), activation and coupling $(2+3)$, capping (4), oxidation (5). After each step, excess of chemicals are removed by washing with dichloroethane or acetonitrile. In the detritylation step (1) cleavage of the protecting group (DMTr) is performed with $1 \%$ dichloroacetic acid in dichloroethane providing a free 5'-hydroxyl group. Since the DMTr cation produces a strong orange colouration under acidic conditions, the absorption at $436 \mathrm{~nm}$ can be used to estimate the coupling efficiency of each step. The coupling step (3) involves a condensation reaction between two nucleotide units. The phosphite group of the phosphoramidite is not reactive towards hydroxyl groups but is easily activated by the weak acid $1 \mathrm{H}$-tetrazole (3) which converts the amidite into a tetrazolide. After coupling, any unreacted 5'-hydroxyl groups are capped as acetates using a mixture of acetic anhydride, 4-dimethylaminopyridine, and 2,4,6-collidine in acetonitrile (4). This capping procedure ensures that only chains with the right sequence can grow in the following coupling steps. Before starting the next cycle, the phosphite triester is oxidized to the more stable phosphate triester using a mixture of iodine, collidine, and water in acetonitrile (5). At the end of the synthesis, the oligonucleotide is separated from the solid support, and base protecting groups are removed with conc. aq. $\mathrm{NH}_{3}$ at $55^{\circ} \mathrm{C}$ overnight (6).

Figure 1

transfer (FRET). ${ }^{8}$ Whereas the latter represents a tool to measure distances in DNA and RNA and thus providing three-dimensional structural information, the quenching / dequenching phenomenon can be used for monitoring DNA cleavage reactions. In addition to techniques such as DNA fingerprinting or mapping ${ }^{10-12}$ and sequencing ${ }^{13-15}$ of genes there exist in situ hybridization techniques which can provide information about gene deletions and translocations as well as chromosome translocations. In the field of RNA, hybridization techniques have been used to determine mRNA distributions on the cellular and subcellular level or to monitor gene expression. ${ }^{16}$ The sensitivity of a fluorescent probe used for in situ hybridization experiments is determined not only by the spectroscopic properties of the dye itself but also by the target specificity of the probe and the stability of the probe-target duplex. ${ }^{17}$
Incorporation of multiple fluorescent building blocks at specific sites of an oligonucleotide may increase its sensitivity, ${ }^{18-20}$ but in some cases it is also known to quench the fluorescence and decrease the extinction coefficient of the dye. $^{21,22}$ Furthermore, since even one dye molecule can perturb the structure of the probe-target duplex, several bulky fluorescent residues often considerably reduce the melting point of a double stranded oligomer and thus decrease duplex stability. ${ }^{18,23}$

A broad range of substituted fluorescent dyes suitable for labeling nucleic acids is available including fluorescein, rhodamine, acridine, dansyl, coumarin, phenazine, oxazine and cyanine dyes as well as polyaromatic compounds like anthracene or pyrene (Figure 2). 
<smiles>O=C(O)c1cc([N+](=O)[O-])ccc1-c1c2ccc(=O)cc-2oc2cc(O)ccc12</smiles><smiles></smiles>

c)

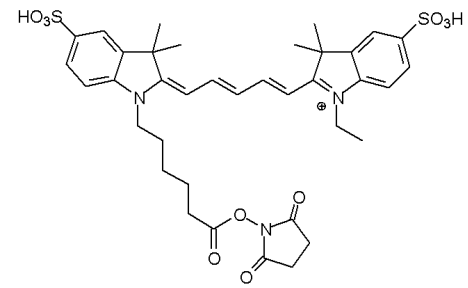

d)

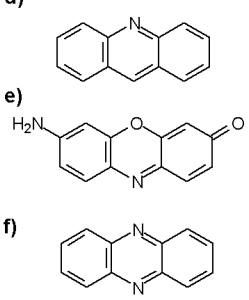

g)<smiles>Cc1cc(=O)oc2cc(N)ccc12</smiles>

Frequently used dyes: a) fluorescein-5-isothiocyanate (FITC Isomer I); b) 5-carboxytetramethylrhodamine (5-TAMRA); c) CY-5-succinimidylester and $\mathrm{h}$ ) dansylchloride. The basic structure of d) acridines; e) oxazines; f) phenazines and g) coumarins. A great number of derivatives of these dyes is commercially available. ${ }^{24}$

Figure 2

A small selection containing spectroscopic properties is given by Waggoner ${ }^{25}$ and Mayer ${ }^{26}$ representing the whole visible spectrum of light. Today the development of new dyes is obviously heading towards the infrared region allowing the employment of less expensive photodiode detector systems and improving the signal-to-noise ratio. ${ }^{27,28}$ Additionally, new energy transfer dyes consisting of both a fluorescein and a rhodamine derivative show improved performance for low concentration detection of nucleic acids, e.g. for DNA sequencing (Figure 3). ${ }^{29}$ Also, thermodynamically stable charge-transfer complexes of transition metal ions with high fluorescence emission, large Stokes shift and elongated life times up to $2 \mu$ s were coupled to oligonucleotides (Figure 4). ${ }^{30,31}$ Those properties are advantageous since they considerably improve the signal-to-noise ratio and thereby the detection limit.

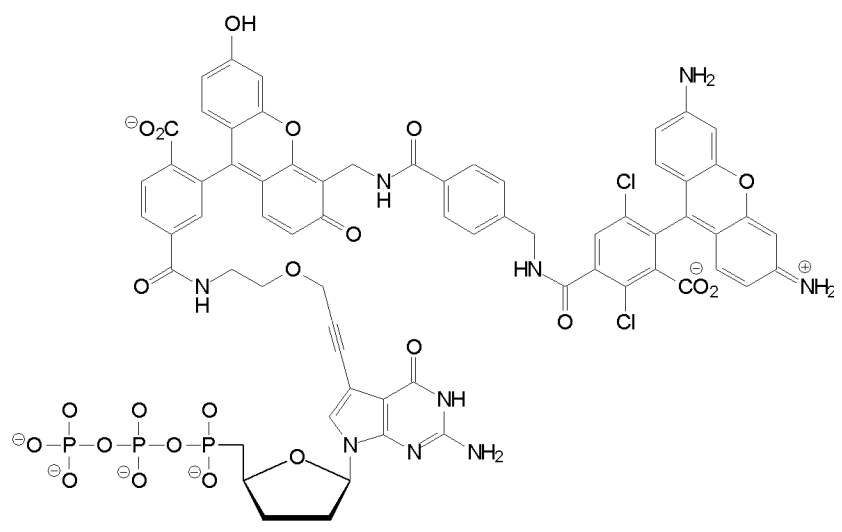

Chemical structure of the ABI BigDye G-terminator

Figure 3

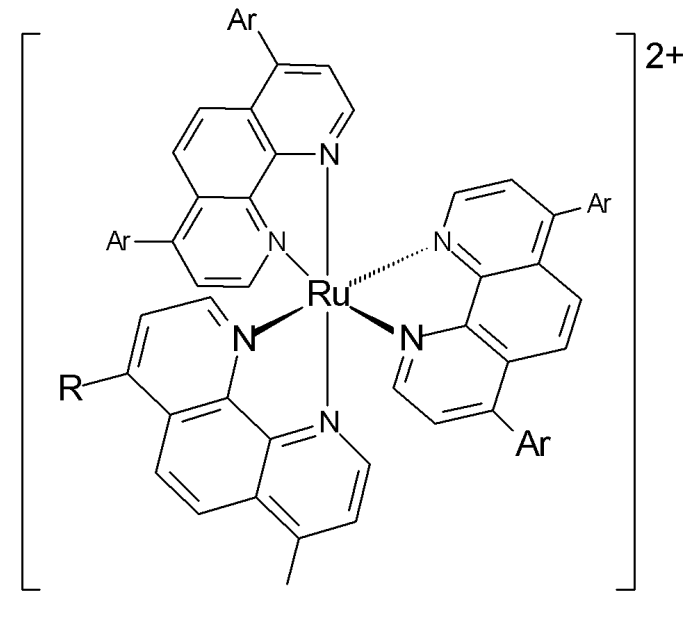

A thermostable bathophenanthroline-ruthenium(II) complex according to Bannwarth. ${ }^{30} \mathrm{Ar}=\mathrm{Aryl} ; \mathrm{R}=$ alkyl linker arm with a terminal carboxyl group for amide coupling

Figure 4

\section{Non-Covalent Labeling Techniques}

Employing intercalating dyes certainly is the simplest way to make DNA visible. Intercalators are specified by non-covalent, reversible interactions with nucleic acids based on hydrophobic as well as electrostatic effects. Typically, they are planar, polyaromatic compounds with cationic residues. The hydrophobic residue enables stacking with nucleobases whereas the ionic residue takes part in interactions with the phosphate backbone. Since intercalators are capable of nesting between base-pairs when mixed with DNA, no covalent binding between fluorophore and nucleic acid is necessary. Although intercalators interfere with neither the major nor the minor groove and even show some interactions with single stranded DNA, they still need the cavity of two hybridized DNA strands for optimal labeling efficiency and sufficient brightness. Typical intercalating fluorescent dyes are ethidium bromide (Figure 5), acridines, thiazole orange, phenazines as well as combinations of them for the purpose of energy transfer experiments. ${ }^{32-34}$

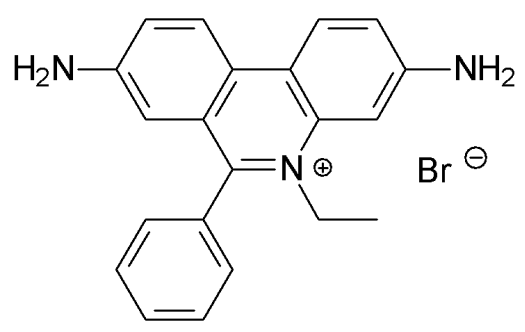

Chemical structure of the DNA-intercalating dye ethidium bromide

Figure 5 


\section{5}

\section{Covalent Labeling Techniques}

Methods for covalent labeling of oligonucleotides may generally be classified in pre- or post-synthetic strategies (Figure 6). The former strategy incorporates a probebound compound into the oligonucleotide during its chemical synthesis. The probe is attached to a monomer prior to the condensation step. The latter strategy incorporates a reactive group and connects the finished DNA with the probe afterwards, utilizing the reactive group. Possible labeling sites within the oligonucleotide are depicted in Figure 7 .

A

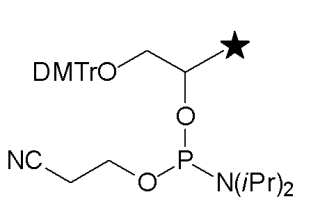

$\downarrow$ Oligonucleotide synthesis $\downarrow$

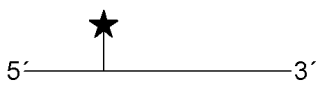

B

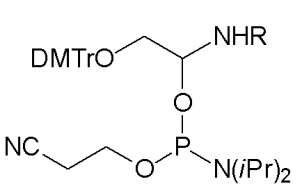

(1)
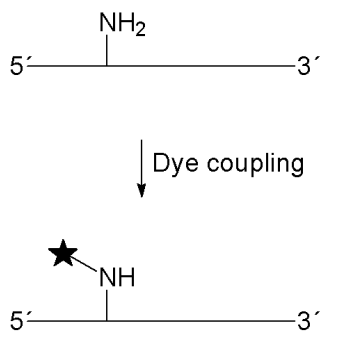

Pre- and post-synthetic labeling procedures. In pre-synthetic techniques (A) a labeled monomer building block is incorporated into the growing oligonucleotide chain, whereas post-synthetic labeling (B) requires a reactive group, e.g. an amino group, which has to be introduced to the oligonucleotide and is afterwards functionalized with a dye. $\mathrm{R}=$ amino protecting group; DMTr = dimethoxytrityl; the star represents the fluorophore

Figure 6

\subsection{Post-Synthetic Strategies}

5.1.1 Reaction of Dyes with Oligonucleotides Bearing a Reactive Group

Up to now, it is not possible to distinguish between the reactivities of identical monomeric units in a DNA or RNA strand. Therefore, providing a reactive group is essential for a post-synthetic labeling procedure if unspecific reactions are not desirable. The conditions for the labeling step have to be considered since oligonucleotides are easily hydrolyzed under acidic conditions or elevated temperatures and dissolve only in water and some organic solvents like acetonitrile, DMSO or DMF. Thus, a primary aliphatic amino group is most often used, although a thiol may be more adequate for some applications. Specific reaction conditions have to be chosen to label this extra ami-

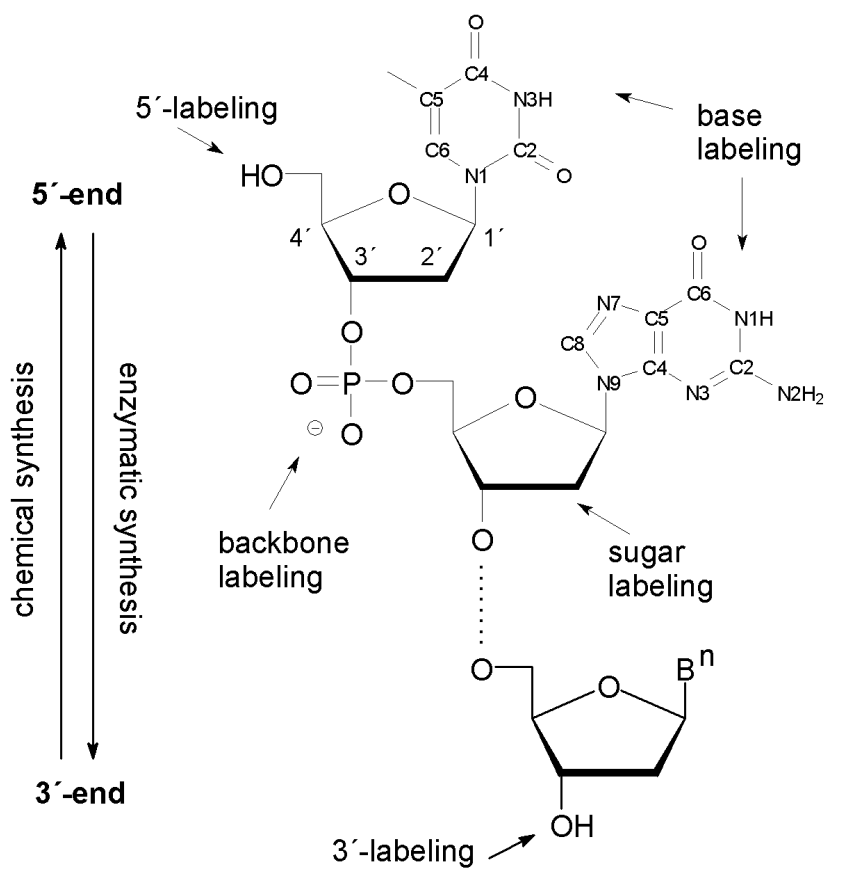

Schematic representation of an oligonucleotide strand and numbering of the base and sugar residues. The arrows indicate the possible sites for labeling. The nucleic acid synthesis in vivo is heading in $5^{\prime} \rightarrow 3^{\prime}$ direction, the chemical synthesis of oligonucleotides starts with the $3^{\prime}$ end.

Figure 7

no group without affecting the less nucleophilic exocyclic aromatic amino groups of the nucleobases. For this purpose, the use of isothiocyanate derivatized fluorescent dyes proved to be the method of choice. Hence, fluorescein isothiocyanate (FITC) is not only the most famous marker for peptide analytics but also for oligonucleotide labeling. The aqueous, bicarbonate buffered amino oligonucleotide solution (pH 9-10) is combined with a solution of the dye in dimethylformamide giving the dye-labeled oligonucleotide overnight in moderate yield. To overcome the insolubility of most fluorescent dyes in water, new dyes with ionic residues are developed. These dyes are commercially available as active esters like succinimide or maleimide, as sulfonyl chlorides or as thiol reactive iodo- and bromoacetamides. ${ }^{25}$

\subsubsection{5'-Modified Oligonucleotides}

5'-Amino-modifiers consist of a $\beta$-cyanoethyl phosphoramidite for automated DNA synthesis and a primary amine serving as reactive group for post-labeling strategies and can be obtained from different commercial suppliers (Figure 8). The monomethoxytrityl or the trifluoroacetyl protecting group is easily removed and the linker connecting the amino group with the nucleic acid residue is of variable length according to the need of the reporter group. ${ }^{35}$ Alternatively, 3 '-phosphoramidites of $5^{\prime}$-amino-5'-deoxynucleosides were applied for DNA se- 
quencing with labeled primers ${ }^{36}$ or polymerase mechanism investigations. ${ }^{37}$<smiles>[R]NCCCOP(N=[R20])OCCC#N</smiles>

Chemical structure of a 5'-amino-modifier phosphoramidite, which is commercially available from Glen Research ${ }^{38} \mathrm{R}=$ amino protecting group (4-monomethoxytriphenylmethyl; trifluoroacetyl)

Figure 8

$5^{\prime}$-modifiers lack the necessary hydroxyl group for further chain elongation, therefore they are only employed at the final step of oligonucleotide synthesis.

\subsubsection{Internal Modifiers}

Internal modifiers offer the possibility to incorporate the label at any position within the sequence. This is especially important when the position of the dye is crucial for the kind of application or the detection system. Energy transfer experiments for example require well-defined distances between donor and acceptor dyes. ${ }^{39-41}$ Internal modifying nucleoside 3'-phosphoramidites bear a dimethoxytrityl group that can be removed after the coupling step revealing a free hydroxyl group to continue the synthesis in $5^{\prime}$-direction. The base, commonly a thymine, is functionalized with a C-6 or C-2 linker that ends with a primary amino group (Figure 9$){ }^{17-19,42-44}$

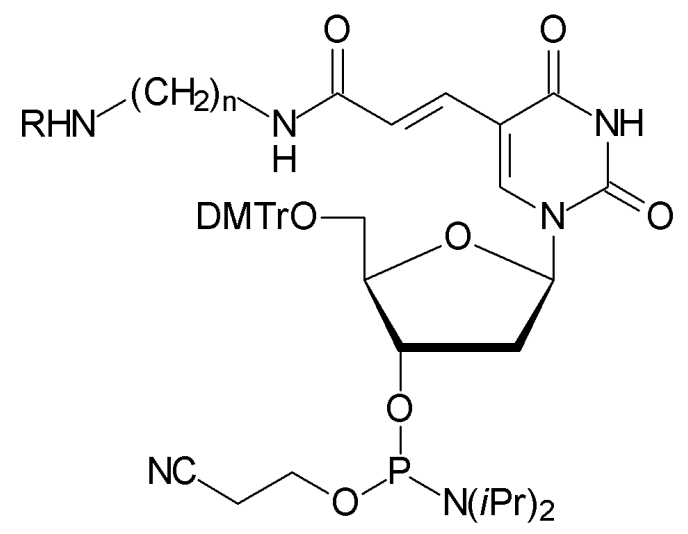

Chemical structure of an internal modifier according to Randolph et al. ${ }^{17} \mathrm{R}=$ amino protecting group; $\mathrm{n}=3,6$

Figure 9

\subsubsection{3'-Modified Oligonucleotides}

In some applications, it is desirable to have a fluorescent dye at the 3 '-terminus of the oligonucleotide leaving the $5^{\prime}$-end unmodified. For this purpose, controlled pore glass as a solid support functionalized with a protected amine for post-synthetic dye coupling and a dimethoxytrityl protected hydroxyl group for standard nucleoside coupling can be employed (Figure 10).<smiles>FC(F)NCC(CO[Ga])O[Te]</smiles>

Amino modified controlled pore glass (CPG) as a solid support which provides a reactive group for 3'-post-labeling (commercially available from Glen Research ${ }^{38}$ )

Figure 10

For investigations on DNA - protein interactions, covalent coupling of nucleic acids to amino acids under mild conditions is often required. Disulfide exchange is a principle reaction applied by nature. Since proteins almost always contain sulfides, disulfide exchange reactions are an excellent approach for DNA - protein binding if the oligonucleotide also carries a sulfide. Similarly, the disulfide exchange reaction is used to introduce fluorescent dyes into the 3 '-terminus of DNA as shown in Figure $11 .{ }^{45}$

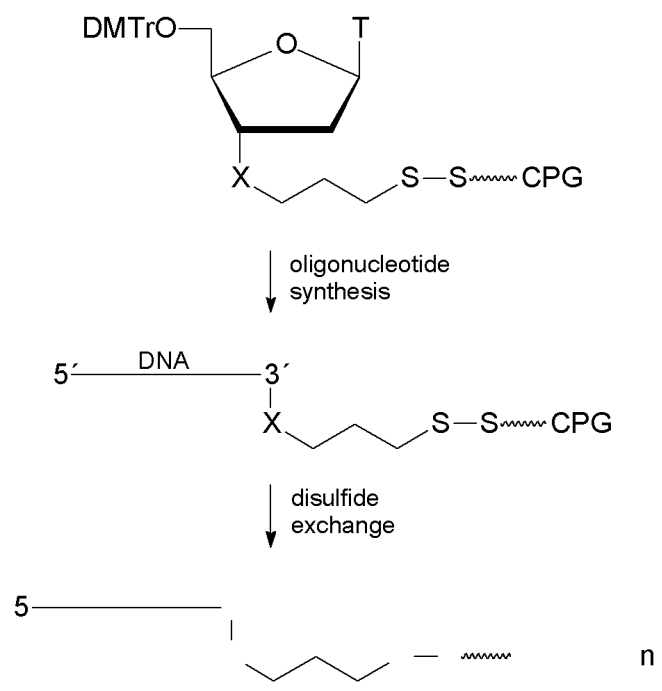

Schematic representation of 3'-labeling via disulfide bridges according to Zuckermann.$^{45}$ During oligonucleotide synthesis the growing chain is immobilized on the solid support $(\mathrm{CPG}=$ controlled pore glass). After synthesis and reduction of the disulfide the generated thiol enables 3 -post-labeling by a disulfide exchange reaction. $\mathrm{X}=\mathrm{S}$, $\mathrm{OP}(\mathrm{O})_{2} \mathrm{O}$

Figure 11

\subsubsection{Backbone Modification}

In contrast to the manifold possibilities of sugar and base labeling, only a small number of approaches deal with labeling of the DNA phosphate backbone reflecting the weak reactivity and the impact of substituents on the 
structure and hybridization capability of DNA. The reactivity is much better when sulfur is substituted for one of the non-bridging oxygen atoms. These so-called phosphorthioate-oligonucleotides are successful in the antisense research since they improve the stability of DNA against enzymatic degradation. They are readily obtained when the oxidation step during synthesis is performed with sulfur instead of iodine. McLaughlin and co-workers presented a protocol that allows labeling of DNA consisting entirely of a phosphorthioate backbone after gel electrophoretic separation. ${ }^{46-48}$ The DNA imbedded in the gel matrix is alkylated with a solution of monobromobimane. This procedure offers two advantages: first the structure of the DNA is not affected by a reporter group until needed and second an increase in fluorescence emission is observed due to the possibility to alkylate each phosphorthioate and thus introduce multiple fluorescent markers.

Another approach for backbone labeling is the introduction of hydrogen phosphonates during or after the oligonucleotide synthesis and subsequent oxidation with ethylenediamine. The free primary amine serves as a target for the fluorescent marker. ${ }^{49}$

\subsection{Pre-Synthetic Strategies}

Procedures employing phosphoramidites of fluorescent compounds can be considered as pre-synthetic labeling methods since the probe is chemically bound to the building block before the oligonucleotide is synthesized.

\subsubsection{Modifications at the Sugar Residue}

In all commercial oligonucleotide synthesis approaches the 4,4'-dimethoxytrityl group (DMTr) is applied for protection of the 5'-hydroxyl function (Figure 1). However, with only a slight change in its chemical structure Fourrey et al. have prepared a fluorescent acid-labile protecting group (Figure 12 a). ${ }^{50}$ Since one phenyl residue of the DMTr group was substituted by pyrenyl, the resulting 1,1 bis-(4-methoxyphenyl)-1'-pyrenyl methyl protecting group emitted fluorescence light at $390 \mathrm{~nm}$. This new protecting group could easily be used to label an oligonucleotide at its $5^{\prime}$-end in the last reaction cycle and provided an alternative detection possibility to localize the desired synthetic product on a polyacrylamide gel or in HPLC separation. Since failure sequences resulting from inefficient coupling steps would not carry this protecting group (and thus are non-fluorescent), the identification of the desired sequence is very much simplified. Furthermore, routinely used short UV light for oligonucleotide detection that is able to cause DNA damages, can be avoided.

This method is an example for facilitating the synthesis and purification of oligonucleotides. However, in most cases fluorescent reporter groups are needed for the application in biochemical experiments such as hybridization techniques or DNA sequencing.
Yamana et al. described several methods for introducing pyrenes via short linkers like methylene, to a $3^{\prime}$ - or $5^{\prime}$-terminal hydroxyl group of oligonucleotides. ${ }^{51}$ The incorporation to the $5^{\prime}$-end was initiated by preparation of $5^{\prime}-(1-$ pyrenylmethyl)thymidine, followed by conversion to the phosphorobisdiethylamidite derivative which was subsequently applied for oligonucleotide synthesis. On the other hand, pyrene labeling at the $3^{\prime}$-end of oligonucleotides was achieved by preparation of $5^{\prime}$-dimethoxytrityl $3^{\prime}-(1-$ pyrenylmethyl)uridine which was bound via its $2^{\prime}$-hydroxyl group to silica as solid support (Figure $12 \mathrm{~b}$ ). The short linker prevented fluorescence quenching caused by stacking with the nucleobases as observed by others who used longer linkers. ${ }^{52}$

In other findings, the utilization of the $2^{\prime}$-hydroxyl ${ }^{53}$ or amino group for tethering probes were reported, for anthracene, ${ }^{54}$ dansyl (Figure $12 \mathrm{c}$ ), ${ }^{55}$ and a 6-dimethylamino2-naphthamide group. ${ }^{56}$
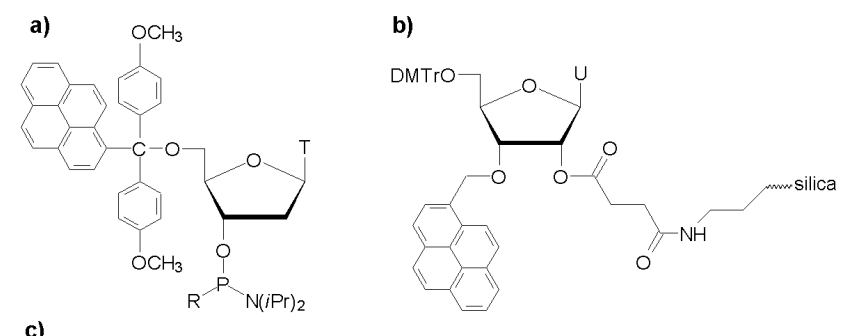

c)

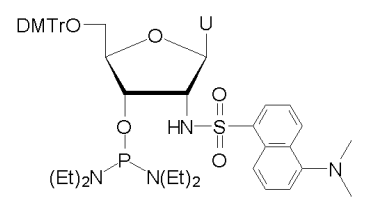

Chemical structures of three fluorescence labeled monomer building blocks with modification at the hydroxyl groups of the sugar. a) a phosphoramidite with a fluorescent acid labile 5 '-protecting group, $\mathrm{R}$ $=\mathrm{CH}_{3}, \mathrm{OCH}_{3},{ }^{50} \mathrm{~b}$ ) pyrene modification of a solid support bound nucleoside $;{ }^{51} \mathrm{c}$ ) a dansyl label coupled to the $2^{\prime}$-position. ${ }^{50}$

\section{Figure 12}

\subsubsection{Modifications at the Base Residue}

There are several approaches to attach a marker molecule to the base residue. Traditionally, modifications were introduced at the $\mathrm{C}-5$ atom in the pyrimidine series and C-8 in the purine series. This is, maybe, due to the fact, that these positions are not involved in base pairing. Furthermore, the only possible position for electrophilic substitution reactions in a pyrimidine ring is $\mathrm{C}-5$, and in a purine ring system, the most reactive site for such modifications is C-8. However, if the purine backbone is replaced by 7deaza analogues, the generated C-7-atom can be used to introduce spacers (Figure 3). The site for modification strongly depends on the application. For example, since carcinogenic effects caused by polycyclic aromatic hydrocarbons can result from alkylation of DNA at the exocyclic amino groups of the bases, Casale et al. prepared 
oligonucleotides containing a 9-methylanthracene residue at the $N^{2}$-position of a single guanosine nucleotide. ${ }^{57}$ Since the fluorescence properties of the anthracene residue depend on the nature of its environment, a short oligonucleotide modified like this provides a useful tool for in vivo studies of DNA replication and repair. The conditions of the chemical coupling reactions have to be adapted if modified phosphoramidites are involved. Casale et al. for example could in part compensate for the poor coupling yield by increasing the reaction time more than 50fold. Under these conditions they achieved coupling yields of $65-70 \%$ compared with over $99 \%$ for standard coupling.

During the last years, the exocyclic amino functions in purine and pyrimidine bases have become more and more attractive for attachment of reporter groups. This is, maybe, due to the fact that modifications at these positions can be achieved in a convenient way under mild conditions. Sigmund et al. prepared labeled phosphoramidites of $2^{\prime}$ deoxyadenosine (Figure 13 a), 2'-deoxyguanosine, and 2 '-deoxycytidine by coupling the amino groups with fluorescein via a carbamoyl spacer. ${ }^{58}$ The authors showed that the various $\mathrm{NH}_{2}$-functions in common nucleosides can be activated by treatment with phenoxycarbonyltetrazolide, which resulted in conversion of the free amino group to the corresponding urethane. These intermediates easily reacted with 5-aminofluorescein in good yields. Maier et al. bound a fluorescein molecule and its quencher 2,4-dinitroaniline to a single base, i. e. at the exocyclic amino function of a guanosine residue before converting this 2'-deoxynucleoside analogue to its corresponding phosphoramidite. ${ }^{59}$ In hybridization experiments, the fluorescence quantum yields increased about 4 - 5 fold, when labeled oligonucleotides of this kind formed a duplex with the target sequences (Figure 13b).

In order to prove whether oligonucleotides with modified base analogues at the nascent 3 '-end are accepted as primers by DNA polymerases, Markiewicz et al. have synthesized an $N^{4}$-modified cytidine by conversion of an $\mathrm{N}^{4}$ arylsulfonylcytosine residue with the primary amine 1,2bis(2-aminoethoxy)ethane to form $5^{\prime}$-O-dimethoxytrityl$N^{4}$-(8-amino-3,6-dioxaoctyl)-2'-deoxycytidine. ${ }^{60}$ After derivatization of the terminal primary amino group with fluorescein isothiocyanate, the nucleoside was converted to its $3^{\prime}$-succinate and bound to CPG support, which was used in oligonucleotide synthesis according to the phosphoramidite approach. The obtained 3'-labelled oligodeoxyribonucleotides were applied as primers in enzymatic DNA sequencing techniques. The 3'-modification did not show any detectable influence on the specificity of incorporation compared to the usually applied 5'-labeled sequencing primers.

The employment of nucleobases with sufficient intrinsic fluorescence is an alternative approach for labeling oligonucleotides. An overview of such analogues was recently published. ${ }^{2}$ Among the most widely used moieties are 2aminopurine, ${ }^{61,} 62$ ethenoadenosine, ${ }^{63}, 64$ and $2^{\prime}$ deoxyisoinosine $\mathrm{e}^{65}$ (Figure $14 \mathrm{~d}, \mathrm{a}, \mathrm{b}$ ). The synthesis of a

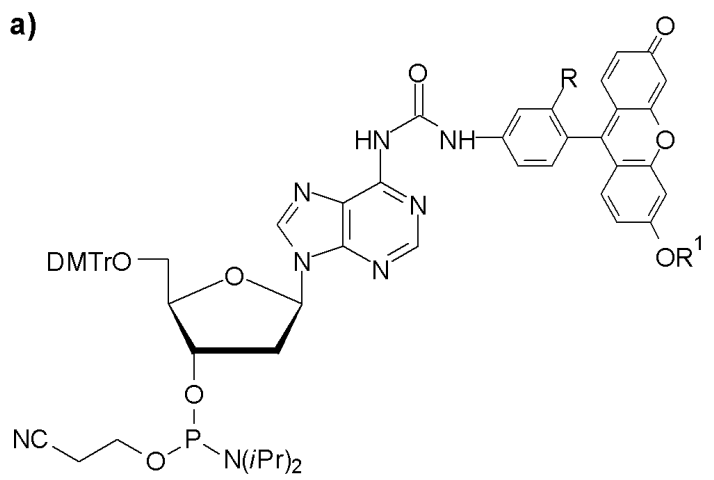

b)

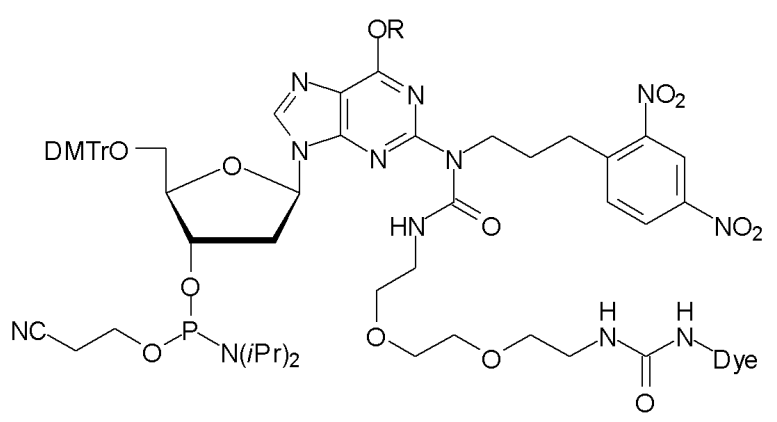

Modification at the exocyclic amino functions of the heterocyclic bases. a) an adenosine analogue according to Sigmund. $.^{58} \mathrm{R}=-\mathrm{C}(\mathrm{O}) \mathrm{O}-$ Npe, $R^{1}=$ Npe; $b$ ) a guanosine analogue according to Maier. ${ }^{59} \mathrm{R}=$ Npe $;$ Dye $=$ Fluorescein $-(\mathrm{Npe})_{2} \mathrm{Npe}=\mathrm{p}$-Nitrophenylethyl

Figure 13

highly fluorescent analogue of ATP, 1, $N^{6}$-ethenoadenosine $5^{\prime}$-triphosphate, was maybe one of the first examples of chemical preparation of a fluorescence-modified nucleotide, its usefulness was based on its ability to substitute ATP in enzyme systems. ${ }^{63}$ Whereas nucleotide analogues with bulky fluorescence residues can cause destabilization of duplexes, 2-aminopurine as a fluorescent probe is of similar structural shape as the natural purines and should therefore not perturb the DNA double helix when paired with thymine. ${ }^{66,67}$ 2-Aminopurine has been used for studying dynamic interactions within DNA by Nordlund et al. ${ }^{66,68}$

In the pyrimidine series, Adams et al. have prepared the fluorescent 2-pyrimidinone-1- $\beta$-D-riboside and incorporated into a chemically synthesized ribozyme sequence (Figure $14 \mathrm{c}$ ). ${ }^{69}$ The fluorescent base was introduced at a site which was not essential for the catalytic cleavage reaction of the ribozyme but nevertheless centrally located in the core of the ribozyme. Mechanistic studies with this modified ribozyme revealed a cleavage rate that was 17.5 fold lower than with an unmodified ribozyme and thus helped to examine the importance of the exocyclic amino function of cytidine which is normally located at this site. 
a)<smiles>[R]n1cnc2c1nc[n+]1cc[nH]c21</smiles>

b)<smiles>[R]n1cnc2c[nH]c(=O)nc21</smiles>

c)<smiles>[R]n1cccnc1=O</smiles>

d)

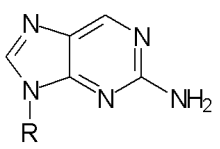

e)<smiles>[R]c1ccc2ccc3cccc4ccc1c2c34</smiles>

f)<smiles>[R]c1cccc2ccccc12</smiles>

g)<smiles>[R]c1ccc2ccccc2c1</smiles>

h)<smiles>[R]c1cc2ccccc2c2ccccc12</smiles>

Fluorescent base residues. a) $1, N^{6}$-ethenoadenosine $;{ }^{63}$ b) isoinosine $;{ }^{65}$ c) 2-pyrimidinone; ${ }^{69}$ d) 2 -aminopurine; ${ }^{61}$ e) 1-pyrenyl; f) 1-naphthyl; g) 2-naphthyl; h) 9-phenanthrenyl; e-g) according to Ren; ${ }^{70} \mathrm{R}=$ sugar moiety

Figure 14

As mentioned above, modified base analogues provide much information about structure and function of nucleic acids. In order to get a better understanding of hydrogen bonding as well as base stacking influence on the stability of a DNA duplex, Ren et al. substituted the heterocyclic bases in natural nucleosides by "base" moieties which are non-polar, weakly hydrogen bonding aromatic groups. ${ }^{70}$ Pyrene, phenanthrene and naphthalene were coupled via C-glycosidic bonds to the 2'-deoxyribose by using a modification of an organocadmium strategy first developed by Schweitzer (Figure 14 e-h). ${ }^{71}$

\subsubsection{Fluorescent Dye Amidites}

Diagnostic applications often require perfect hybridization of oligonucleotides with a target DNA sequence. Therefore, it might be more adequate not to interfere with the nucleobases which are responsible for base pairing. All kinds of phosphoramidites bearing fluorescent dyes like fluorescein derivatives, pyrene residues, acridine or phenazine groups were synthesized for that reason during the past years. These dyes are added to the oligonucleotide without having much influence on the hybridization efficiency. Simple dye phosphoramidites serve as 5'-labeling reagents ${ }^{72-74}$ whereas dye phosphoramidites additionally providing a dimethoxytrityl protected hydroxyl group are employed when the label is to be set at an internal position of the DNA. For 3'-labeling, dyes were also coupled to the solid support. ${ }^{75}$

\subsection{Enzymatic Methods}

A number of modified nucleoside 5'-triphosphates can serve as substrates for enzymes involved in DNA or RNA synthesis for labeling oligonucleotides. The main advantages of enzymatic methods are their mild reaction conditions combined with high specificity and efficiency. It is known that terminal transferase and T4 RNA ligase accept

a variety of modified nucleotides as substrate, adding them to the $3{ }^{\prime}$-ends of DNA or RNA. ${ }^{76-79}$

Kinjo et al. have synthesized the fluorescent nucleotide analogue $2^{\prime}$ - $O$-anthraniloylcytidine $3^{\prime}, 5^{\prime}$-diphosphate to elongate the 3 '-terminus of various oligoribonucleotides including tRNAs using T4 RNA ligase. ${ }^{80}$ The yields of the enzymatic ligation step were up to $57 \%$ using single strand oligoribonucleotides and about $30 \%$ in labeling tRNAs. Modifications at the base moiety are believed to interfere in base-base interactions, therefore the incorporation of the fluorescent anthraniloyl residue at the sugar residue appears to be more advantageous. The above mentioned techniques are convenient for $3^{\prime}$-end-labeling, even though for some approaches it is important to leave the 3 '-end intact for further extension. For this purpose, Kinoshita et al. have modified the T4 RNA ligase reaction to facilitate labeling of the $5^{\prime}$-end (Figure 15). The enzyme normally catalyzes the ligation of a $5^{\prime}$-monophosphorylated donor DNA sequence and an acceptor DNA sequence with a free 3'-hydroxyl group under participation of ATP. In a first step, AMP is ligated to the donor, and this intermediate reacts with the acceptor under formation of an internucleotidic phosphate bridge in a second step, which releases AMP. Without an acceptor in the reaction mixture, the intermediate product will accumulate and can be isolated afterwards. If $2^{\prime}$-aminopurine is substituted for the natural substrate ATP, the nucleoside-donor adduct becomes fluorescent. ${ }^{81}$

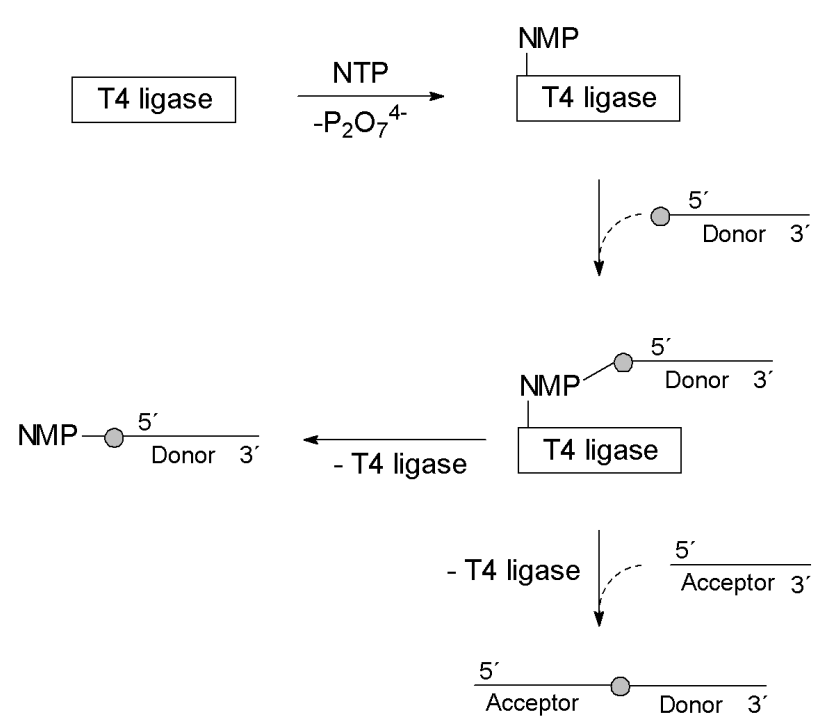

Schematic representation of the ligation reaction of the T4 RNA ligase according to Kinoshita. ${ }^{81}$ NTP $=$ nucleoside- $5^{\prime}$-triphosphate; $\mathrm{NMP}=$ nucleoside $-5^{\prime}$-monophosphate with $\mathrm{N}=$ adenine or $2^{\prime}$-aminopurine; the filled circle $(\bullet)$ represents a phosphate unit. After complexation of the enzyme T4 ligase with the NMP, the nucleotide is added to the $5^{\prime}$-end of the donor oligonucleotide. Normally, this enzyme-oligonucleotide complex reacts with an acceptor strand under formation of an internucleotidic phosphodiester bridge. If the acceptor is not present in the reaction mixture, the nucleoside is ligated to the donor strand via a pyrophosphate bridge and released.

Figure 15 
DNA polymerases accept various 2'-deoxynucleoside-5'triphosphates with modified base and sugar residues as substrates. ${ }^{60,82-87}$ Those fluorescent analogues are used in enzymatic DNA sequencing. Automated techniques refer to a variation of traditional Sanger sequencing, ${ }^{88}$ like in the ABI approach where four differently labeled dye terminators are utilized. ${ }^{89}$ The fluorescent dyes are introduced via alkine linkers attached to the $\mathrm{C}-5$ base position in the pyrimidine series and the $\mathrm{C}-7$ position in the deaza purine series (Figure 3).

Although the exocyclic amino functions were assumed to be important for Watson-Crick base pairing it has been shown that cytidine terminators labeled at the exocyclic $\mathrm{NH}_{2}$-group act as substrates for DNA-polymerases with perfect termination quality. ${ }^{90}$ By choosing this position, modifications can easily be introduced into the uridine or cytidine precursors.

If enzymatic techniques are to be used, it always has to be considered that the acceptance of non-natural substrates may dramatically alter. For example, Zhu et al. have demonstrated the dependence of incorporation efficiency on linker lengths between nucleobases and cyanine dyes in the polymerase chain reaction (PCR) ${ }^{91}$

A further possibility for introducing labels at the $5^{\prime}$-end is a post-synthetic phosphorylation and substitution of the synthesized and purified oligonucleotide. DNA can be enzymatically phosphorylated at the 5'-hydroxyl group with polynucleotide kinase from bacteriophage T4 and ATP. Subsequently, the phosphate is activated with $N$-methylimidazole which is easily substituted by ethylenediamine providing a free primary amino group for fluorescent dye labeling. ${ }^{92}$ When ATP- $\gamma$-S is used instead of ATP, the enzyme transfers a thiophosphate unit onto the oligonucleotide. The resulting thiophosphate needs no further activation since sulfur couples readily with $\alpha$-bromo- or iodoacetyl functionalized dyes in a nucleophilic substitution reaction. ${ }^{1}$

\section{Conclusion}

Three main strategies exist for the covalent labeling of oligonucleotides with fluorescent probes. These are the post- and the pre-synthetic as well as the enzymatic methods. Within the chemical strategies, the automated solid phase DNA synthesis is an excellent technique for introducing all kinds of modifications at any position of the oligonucleotide sequence.

Today, a scientist has the choice between hundreds of different dyes that cover the whole visible spectrum of light. These dyes differ greatly in their chemical and physical properties. It is of considerable interest to design dyes with improved photochemical stability, excitation and emission wavelengths in the near infrared region, high quantum yield combined with compatibility in aqueous medium. These dyes, together with the development of powerful optical systems, are the basis for the forthcom- ing revolution in instrumental DNA and RNA analysis: the miniaturization of the detection systems to the size of microchips. This progress will in turn facilitate the automation in routine DNA diagnostics. At the present, no other technique than fluorescence detection is more appropriate meeting these requirements.

\section{References and Notes}

(1) Hill, J. J.; Royer, C. A. Methods Enzymol. 1997, 278, 390-416

(2) Jameson, D. M.; Eccleston, J. F. Methods Enzymol. 1997, 278, 363-390

(3) Beaucage, S. L.; Iyer, R. P. Tetrahedron 1992, 48, 2223-2311

(4) Beaucage, S. L.; Iyer, R. P. Tetrahedron 1993, 49, 1925-1963

(5) Beaucage, S. L.; Iyer, R. P. Tetrahedron 1993, 49, 6123-6194

(6) Caruthers, M. H.; Barone, A. D.; Beaucage, S. L.; Dodds, D. R.; Fisher, E. F.; McBride, L. J.; Matteucci, M.; Stabinski, Z.; Tang, J.-Y. Methods Enzymol. 1987, 154, 287-313

(7) Steinlechner, H.; BioSpring GmbH, Frankfurt/M 1999, personal communication

(8) Lee, S. P.; Han, M. K. Methods Enzymol. 1997, 278, 343-362

(9) Weiss, S. Science 1999, 283, 1676-1682

(10) Fujii, M.; Ogata, T.; Takahashi, E.; Yamada, K.; Nakabayashi, K.; Oishi, M.; Ayusawa, D. FEBS Lett. 1995, 375, 263-267

(11) Lawrence, J. B.; Villnace, C. A.; Singer, R. H. Cell, 1988, 52, 51-61

(12) Pinkel, D.; Straume, T.; Gray, J. W. Proc. Natl. Acad. Sci. USA 1986, 83, 2934-2938

(13) Smith, L. M.; Sanders, J. Z.; Kaiser, R. J.; Hughes, P.; Dodd, C.; Connell, C. R.; Heiner, C.; Kent, S. B.; Hood, L. E. Nature 1986, 321, 674-679

(14) Prober, J. M.; Trainor, G. L.; Dam, R. J.; Hobbs, F. W.; Robertson, C. W.; Zagursky, R. J.; Cocuzza, A. J.; Jensen, M. A.; Baumeister, K. Science 1987, 238, 336-341

(15) Ansorge, W.; Sproat, B.; Stegemann, J.; Schwager, C.; Zenke, M. Nucleic Acids Res. 1987, 15, 4593-4602

(16) Yu, H.; Ernst, L.; Wagner, M.; Waggoner, A. Nucleic Acids Res. 1992, 20, 83-88

(17) For further references see: Randolph, J. B.; Waggoner, A. S. Nucleic Acids Res. 1997, 25, 2923-2929

(18) Haralambidis, J.; Chai, M.; Tregear, G. W. Nucleic Acids Res. 1987, 15, 4857-4876

(19) Brumbaugh, J. A.; Middendorf, L. R.; Grone, D. L.; Ruth, J. L. Proc. Natl. Acad. Sci. USA 1988, 85, 5610-5614

(20) Singh, D.; Vijayanti, K.; Ganesh, K. N. Nucleic Acids Res. 1990, 18, 3339-3345

(21) West, W.; Pearce, S.; Grum, F. J. Phys. Chem. 1967, 71, 13161326

(22) Levinson, G. S.; Simpson, W. T.; Curtis, W. J. Am. Chem. Soc. 1957, 79, 4314-4320

(23) Mineno, J.; Ishino, Y.; Ohminami, T.; Kato, I. DNA Sequence 1993, 4, 135-141

(24) Haugland, R. P., Handbook of fluorescent probes and research chemicals, Molecular Probes, Eugene, sixth edition, 1996

(25) Waggoner, A. Methods Enzymol. 1995, 246, 362-373

(26) Mayer, A.; Neuenhofer, S. Angew. Chem. 1994, 106, 10971126

(27) Sauer, M.; Han, K.-T.; Müller, R.; Nord, S.; Schulz, A.; Seeger, S.; Wolfrum, J.; Arden-Jacob, J.; Deltau, G.; Marx, N. J.; Zander, C.; Drexhage, K. H. J. Fluoresc. 1995, 5, 247-261

(28) Müller, R.; Herten, D. P.; Lieberwirth, U.; Neumann, M.; Sauer, M.; Schulz, A.; Siebert, S.; Drexhage, K. H.; Wolfrum, J. Chem. Phys. Lett. 1997, 279, 282-288

(29) Lee, L. G.; Spurgeon, S. L.; Heiner, C. R.; Benson, S. C.; Rosenblum, B. B.; Menchen, S. M.; Graham, R. J.; 
Constantinescu, A.; Upadhya, K. G.; Cassel, J. M. Nucleic Acids Res. 1997, 25, 2816-2822

(30) Bannwarth, W.; Schmidt, D.; Stallard, R. L.; Hornung, C.; Knorr, R.; Müller, F. Helv. Chim. Acta 1988, 71, 2085-2099

(31) Hurley, D. J.; Tor, Y. J. Am. Chem. Soc. 1998, 120, 2194-2195

(32) Benson, S. C.; Mathies, R. A.; Glazer, A. N. Nucleic Acids Res. 1993, 21, 5720-5726

(33) Zamaratski, E.; Chattopadhyaya, J. Tetrahedron 1998, 54, 8183-8206

(34) LePecq, J. B.; Paoletti, C. J. Mol. Biol. 1967, 27, 87-106

(35) Glen Research, User Guide to DNA modification, 1996. Examples: Chehab, F. F.; Kan, Y. W. Proc. Natl. Acad. Sci. USA 1989, 86, 9178-9182; Trebesius, K.; Harmsen, D.; Rakin, A.; Schmelz, J.; Heesemann, J. J. Clin. Microbiol. 1998, 36, $2557-2564$

(36) Smith, L. M.; Kaiser, R. J.; Sanders, J. Z.; Hood, L. E. Methods Enzymol. 1987, 155, 260-301

(37) Tyagi, S. C.; Wu, F. Y.-H. J. Biol. Chem. 1987, 262, 1068410688

(38) Glen Research, User Guide to DNA modification, 1996

(39) Ju, J.; Ruan, C.; Fuller, C. W.; Glazer, A. N.; Mathies, R. A. Proc. Natl. Acad. Sci. USA 1995, 92, 4347-4351

(40) Ju, J.; Glazer, A. N.; Mathies, R. A. Nature Medicine 1996, 2, $246-249$

(41) Ju, J.; Glazer, A. N.; Mathies, R. A. Nucleic Acids Res. 1996, $24,1144-1148$

(42) Shealy, D. B.; Lipowska, M.; Lipowska, J.; Narayanan, N.; Sutter, S.; Strekowski, L.; Patonay, G. Anal. Chem. 1995, 67, 247-251

(43) Hagmar, P.; Bailey, M.; Tong, G.; Haralambidis, J.; Sawyer, W. H.; Davidson, B. E.; Biochim. Biophys. Acta 1995, 1244, 259-268

(44) Telser, J.; Cruickshank, K. A.; Morrison, L. E.; Netzel, T. L. J. Am. Chem. Soc. 1989, 111, 6966-6976

(45) Zuckermann, R.; Corey, D.; Schultz, P. Nucleic Acids Res. 1987, 15, 5305-5321

(46) Hodges, R.; Conway, N. E.; McLaughlin, L. W. Biochemistry 1989, 28, 261-267

(47) Conway, N. E.; McLaughlin, L. W. Bioconjugate Chem. 1991, 2, 452-457

(48) Stewart, A. J.; Pichon, C.; Midoux, P.; Mayer, R.; Monsigny, M.; Roche, A. C. New. J. Chem. 1997, 21, 87-98

(49) Murakami, A.; Nakaura, M.; Nakatsuji, Y.; Nagahara, S.; Tran-Cong, Q.; Makino, K. Nucleic Acids Res. 1991, 19, 4097-4102

(50) Fourrey, J. L.; Varenne, J.; Blonski, C.; Dousset, P.; Shire, D. Tetrahedron Lett. 1987, 28, 5157-5160

(51) Yamana, K.; Nunota, K.; Nakano, H.; Sangen, O. Tetrahedron Lett. 1994, 35, 2555-2558

(52) Mann, J. S.; Shibata, Y.; Meehan, T. Bioconjugate Chem. 1992, 3, 554-159

(53) Aurup, H.; Tuschl, T., Benseler, F.; Ludwig, J.; Eckstein, F. Nucleic Acids Res. 1994, 22, 20-24

(54) Yamana, K.; Aota, R.; Nakano, H. Tetrahedron Lett. 1995, 36, $8427-8430$

(55) Yamana, K.; Ohashi, Y.; Nunota, K.; Nakano, H. Tetrahedron 1997, 53, 4265-4270

(56) Yamana, K.; Mitsui, T.; Hayashi, H., Nakano, H. Tetrahedron Lett. 1997, 38, 5815-5818

(57) Casale, R.; McLaughlin, L. W. J. Am Chem. Soc. 1990, 112, 5264-5271

(58) Sigmund, H.; Maier, T.; Pfleiderer, W. Nucleosides Nucleotides 1997, 16, 685-696

(59) Maier, T.; Pfleiderer, W. Nucleosides Nucleotides 1995, 14 961-965
(60) Markiewicz, W. T.; Gröger, G.; Rösch, R.; Zebrowska, A.; Markiewicz, M.; Klotz, M.; Hinz, M.; Godzina, P.; Seliger, H. Nucleic Acids Res. 1997, 25, 3672-3680

(61) Ward, D. C.; Reich, E.; Stryer, L. J. Biol. Chem. 1969, 244 , 1228-1237

(62) Bloom, L. B.; Otto, M. R.; Beechem, J. M.; Goodman, M. F. Biochemistry 1993, 32, 11247-11258

(63) Secrist, J. A.; Barrio, J. R.; Leonhard, N. J. Science 1972, 175 , 646-647

(64) Toulmé, J. J.; Hélene, C. Biochim. Biophys. Acta 1980, 606, 95-104

(65) Seela, F.; Chen, Y. Nucleic Acids Res. 1995, 23, 2499-2505; Seela, F.; Chen, Y.; Bindig, U.; Kazimierczuk, Z. Helv. Chim. Acta 1994, 77, 194-202

(66) Nordlund, T. M.; Andersson, S.; Nilsson, L.; Rigler, R.; Gråslund, A.; McLaughlin, L. W. Biochemistry 1989, 28, 9095-9103

(67) Sowers, L. C.; Fazakerley, G. V.; Erija, R.; Kaplan, B. E.; Goodman, M. F. Proc. Natl Acad. Sci. USA 1986, 83, 54345438

(68) Guest, C. R.; Hochstrasser, R. A.; Sowers, L. C.; Millar, D. P. Biochemistry 1991, 30, 3271-3279

(69) Adams, C. J.; Murray, J. B.; Arnold, J. R. P.; Stockley, P. G. Tetrahedron Lett. 1994, 35, 1597-1600

(70) Ren, R. X.-F.; Chaudhuri, N. C.; Paris, P. L.; Rumney, S.; Kool, E. T. J. Am. Chem. Soc. 1996, 118, 7671-7678

(71) Schweitzer, B. A.; Kool, E. T. J. Am. Chem. Soc. 1995, 117, 1863-1872

(72) Lewis, F. D.; Zhang, Y.; Letsinger, R. L. J. Am. Chem. Soc. 1997, 119, 5451-5452

(73) Korshun, V. A.; Pestov, N. B.; Birikh, K. R.; Berlin, Y. A. Bioconjugate Chem. 1992, 3, 559-562

(74) Schubert, F.; Ahlert, K.; Cech, D.; Rosenthal, A. Nucleic Acids. Res. 1990, 18, 3427

(75) Theisen, P.; McCollum, C.; Upadhya, K.; Jacobson, K.; Vu, H.; Andrus, A. Tetrahedron Lett. 1992, 33, 5033-5036

(76) Igloi, G. L.; Schiefermay, E. Biotechniques 1993, 15, 486-488

(77) Schott, H.; Schrade, H. Eur. J. Biochem. 1984, 143, 613-620

(78) Di Mauro, E.; Costanzo, G.; Negri, R. Nucleic Acids Res. 1994, 22, 3811-3812

(79) Paulsen, H.; Wintermeyer, W. Eur. J Biochem. 1984, 138 , 125-130

(80) Kinjo, M.; Araiso, T.; Koyama, T. Dyes and Pigments 1998, 38, 77-95

(81) Kinoshita, Y.; Nishigaki, K.; Husumi, Y. Nucleic Acids Res. 1997, 25, 3747-3748

(82) Sarfati, S. R.; Namane, A. Tetrahedron Lett. 1990, 31, 25812584

(83) Starke, H. R.; Yan J. Y.; Zhang, J. Z.; Mühlegger, K.; Effgen, K.; Dovichi, N. J. Nucleic Acids Res. 1994, 22, 3997-4001

(84) Voss, H.; Schwager, C.; Wirkner, U.; Zimmermann, J.; Erfle, H.; Hewitt, N. A.; Rupp, T.; Stegemann, J.; Ansorge, W. Methods Mol. Cell. Biol. 1991, 3, 1-9; 30-34; 153-155

(85) Doronin, S. V.; Dobrikov, M. I.; Lavrik, O. I. FEBS Lett. 1992, 313, 31-33

(86) Wlassov, A. W.; Dobrikov, M. I.; Safronov, I. V.; Dudko, R. Y.; Bogachev, V. S.; Kandaurova, V. V.; Sishkin, G. V.; Dymshits, G. M.; Lavrik, O. I. Bioconjugate Chemistry 1995, 6, 352-360

(87) Steffens, D. L.; Jang, G. Y.; Sutter, S. L.; Brumbaugh, J. A.; Middendorf, L. R.; Mühlegger, K.; Mardis, E. R.; Weinstock, L. A.; Wilson, R. K. Genome Research 1995, 393-399

(88) Lee, L. G.; Connell, C. R.; Woo, S. L.; Cheng, R. D.; McArdle, B. F.; Fuller, C. W.; Halloran, N. D.; Wilson R. K. Nucleic Acids Res. 1992, 20, 2471-2483

(89) Patent Corporation Treaty PCT/US90/05565 April 1991 
(90) Stolze, K.; Koert, U.; Klingel, S.; Sagner, G.; Wartbichler, R.; Engels, J. W. Helv. Chim. Acta 1999, in press

(91) Zhu, Z.; Chao, J.; Yu, H.; Waggoner, A. S. Nucleic Acids Res. 1994, 22, 3418-3422

(92) Mergny, J.-L.; Boutorine, A. S.; Garestier, T.; Belloc, F.; Rougée, M.; Bulychev, N. V.; Koshkin, A. A.; Bourson, J.; Lebedev, A. V.; Valeur, B.; Thuong, N. T.; Hélène, C. Nucleic
Acids Res. 1994, 22, 920-928

Azadnia, A; Campbell, R.; Sharma, M. Anal. Biochem. 1994, $218,444-448$

Article Identifier:

1437-2096,E;1999,0,10,1667,1678,ftx,en;T00399ST.pdf 